\title{
NON-TANGENTIAL CONVERGENCE OF THE GENERALIZED POISSON INTEGRAL
}

\author{
A. D. Nakhman ${ }^{1}$, B. P. Osilenker ${ }^{2}$ \\ Departments: "Engineering Mechanics and Machine Parts", TSTU (1); \\ "Higher Mathematics", Moscow State University of Civil Engineering, Moscow (2), \\ alextmb@mail.ru
}

Keywords: exponential summation methods; non-tangential convergence; semicontinuous means.

Abstract: The means of Fourier series $U(f, y ; \lambda, h)$ generated by semi-continuous summation methods $\Lambda=\left\{\lambda_{k}(h), k=0,1, \ldots ; h>0\right\}$ are studied. For the points $(y, h)$, belonging to an angular domain $\Gamma_{d}(x)$, upper estimates of the corresponding maximal operators are obtained. Non-tangential convergence almost everywhere of the generalized Poisson-Abel means, corresponding to a case of $\lambda_{k}(h)=\exp \left(-h k^{\alpha}\right)$, $k=0,1, \ldots ; \alpha \geq 1$, is established.

\section{Introduction. Formulation of the problem}

Let $L_{2 \pi}$ be class of $2 \pi$-periodical functions, which are summable on $[-\pi, \pi]$ and $C^{2}(0,+\infty)$ - class of functions having continuous second derivative on $(0,+\infty)$. In this paper we consider the semi-continuous means

$$
U(f, y ; \lambda, h)=\sum_{k=-\infty}^{\infty} \lambda_{|k|}(h) c_{k}(f) \exp (i k y)
$$

of Fourier series $s[f]$ of functions $f \in L_{2 \pi}$. In the definition (1)

$$
c_{k}(f)=\frac{1}{2 \pi} \int_{-\pi}^{\pi} f(t) \exp (-i k t) d t, k=0, \pm 1, \pm 2, \ldots
$$

are complex Fourier coefficients of function $f$.

The problem of the study of behavior (1) at $h \rightarrow+0$ arises in various problems of analysis and in the case of discrete $h$ it was studied by many authors (see, eg., [1] and references therein). For convex (piecewise-convex) summarizing sequences $\Lambda=\left\{\lambda_{k}(h), k=0,1, \ldots\right\}, \lambda_{0}(h)=1$ and all $f \in L_{2 \pi}$, the convergence of means (1) almost everywhere

$$
\lim _{h \rightarrow+0} U(f, x ; \lambda, h)=f(x)
$$


was established in [2]; in [3] it was studied the behavior of the corresponding means in Lebesgue points.

The result is valid, in particular, for the case of $\lambda_{k}(h)=\exp \left(-h k^{\alpha}\right), \quad k=0,1, \ldots$; $\alpha>0$. An important consequence of this result is the summability almost everywhere of Fourier series of function $f \in L_{2 \pi}$ by Abel-Poisson method ("radial" convergence of Poisson integral, [4, vol. 1, p. 162]), which corresponds to the case of $\alpha=1$. More complicated (and more interesting from the point of view of the theory of analytic functions) is the problem of so-called non-tangential convergence of (1). This is the behavior of $(1)$ at $(y, h) \rightarrow(x, 0)$, when the point $(y, h)$ is within the boundaries of the angular domain

$$
\Gamma_{d}(x)=\left\{(y, h) \mid y \in[-\pi, \pi], \quad h>0, \quad \frac{|y-x|}{h} \leq d\right\}, d=\text { const }, d>0 .
$$

In this paper, under some conditions on the matrix $\Lambda$ :

a) we obtain the maximal inequalities of the means (1);

b) we establish the estimates of $L^{p}$-norms of corresponding maximal operators (in the cases of $p>1, p=1,0<p<1$ );

c) we proof the non-tangential convergence $U(f, y ; \lambda, h) \rightarrow f(x)$ for $f \in L$ and almost all $x$.

\section{The main result}

Define

$$
U_{*}(f, x ; \lambda)=\sup _{(y, h) \in \Gamma_{d}(x)}|U(f, y ; \lambda, h)|
$$

let $m=\left[\frac{1}{2 d h}\right]$ and

$$
f^{*}(x)=\sup _{\eta>0} \frac{1}{2 \eta} \int_{x-\eta}^{x+\eta}|f(t)| d t
$$

be Hardy maximal function $[4$, vol. 1, p. 55].

Theorem 1. Let the sequence $\left\{\lambda_{N}(h)\right\}$ decreases so rapidly that

$$
N\left|\lambda_{N}(h)\right|+N^{2}\left|\Delta \lambda_{N}(h)\right|=o(1), N \rightarrow \infty,
$$

and there is a constant $C=C_{\Lambda, d}$ such that

$$
\sum_{k=0}^{\infty} \frac{(m+k+1)(k+1)}{m}\left|\Delta^{2} \lambda_{k}(h)\right| \leq C .
$$

Then for every $x$ the estimate

$$
U_{*}(f, x ; \lambda) \leq C_{\Lambda, d} \quad f^{*}(x)
$$

holds.

Remark. Here and throughout the paper $C$ will represent constants, which depend only on the explicitly specified indexes.

Let

\section{Proof of the theorem 1}

$$
D_{k}(t)=\frac{1}{2}+\sum_{v=1}^{k} \cos v t=\frac{\sin \left(k+\frac{1}{2}\right) t}{2 \sin \frac{1}{2} t}
$$


and

$$
F_{k}(t)=\frac{1}{k+1} \sum_{v=0}^{k} D_{k}(t)=\frac{\sin ^{2} \frac{k+1}{2} t}{2(k+1) \sin ^{2} \frac{1}{2} t},
$$

be Dirichlet and Fejer kernels, respectively [4, vol. 1, pp. 86, 148].

Applying the Abel's transform twice $[4$, vol.1, p.15] and the obvious estimate

$$
\left|D_{N}(t)\right|+F_{N}(t) \leq 2(N+1), N=0,1, \ldots,
$$

we obtain the relation

$$
\begin{gathered}
|U(f, y ; \lambda, h)|=\left|\lim _{N \rightarrow+\infty} \frac{1}{\pi} \int_{-\pi}^{\pi} f(t)\left\{\frac{\lambda_{0}(h)}{2}+\sum_{k=1}^{N} \lambda_{k}(h) \cos k(y-t)\right\} d t\right|= \\
=\frac{1}{\pi} \mid \lim _{N \rightarrow+\infty}\left\{\lambda_{N}(h) \int_{-\pi}^{\pi} f(y+t) D_{N}(t) d t+N \Delta \lambda_{N-1}(h) \int_{-\pi}^{\pi} f(y+t) F_{N-1}(t) d t+\right. \\
\left.+\sum_{k=0}^{N-2}(k+1) \Delta^{2} \lambda_{k}(h) \int_{-\pi}^{\pi} f(y+t) F_{k}(t) d t\right\} \mid \leq \\
\leq C \lim _{N \rightarrow+\infty}\left\{\left(N\left|\lambda_{N}(h)\right|+N^{2}\left|\Delta \lambda_{N}(h)\right|\right) \int_{-\pi}^{\pi}|f(y+t)| d t+\right. \\
\left.+\sum_{k=0}^{N-2}(k+1)\left|\Delta^{2} \lambda_{k}(h)\right| \int_{-\pi}^{\pi}|f(y+t)| F_{k}(t) d t\right\} .
\end{gathered}
$$

By (2) we have

$$
|U(f, y ; \lambda, h)| \leq C \sum_{k=0}^{\infty}(k+1)\left|\Delta^{2} \lambda_{k}(h)\right| \int_{-\pi}^{\pi}|f(t)| F_{k}(y-t) d t .
$$

Note that the condition $|x-t| \geq 2 h d$ implies the relation

$$
|y-t| \geq|x-t|-d h \geq \frac{1}{2}|x-t|
$$

for all $(y, h) \in \Gamma_{d}(x)$. Consequently, for each fixed $x$ the inequality

$$
|y-t| \geq \frac{1}{2}|x-t|
$$

is satisfied at all $t$, for which

$$
|x-t| \geq \frac{1}{m}
$$

To estimate the right side of (5) we need the following obvious inequality:

$$
\frac{1}{\pi} \int_{-\pi}^{\pi}|f(t)| d t \leq f^{*}(x), \quad\left|F_{k}(t)\right| \leq C \frac{1}{(k+1) t^{2}}, \quad 0<|t| \leq \pi, k=0,1, \ldots ;
$$

Now, in view of (4) and (8) we have

$$
\sum_{k=0}^{\infty}(k+1)\left|\Delta^{2} \lambda_{k}(h)\right| \int_{-\pi}^{\pi}|f(t)| F_{k}(y-t) d t \leq C|| \Delta^{2} \lambda_{0}(h) \mid f^{*}(x)+
$$




$$
\begin{aligned}
& +\sum_{k=1}^{m}(k+1)\left|\Delta^{2} \lambda_{k}(h)\right|\left(\int_{|x-t| \leq 1 / k}|f(t)|(k+1) d t+\int_{1 / k \leq|x-t| \leq 2 \pi}|f(t)| \frac{1}{k(y-t)^{2}} d t\right)+ \\
& +\sum_{k=m+1}^{\infty}(k+1)\left|\Delta^{2} \lambda_{k}(h)\right|\left(\int_{|x-t| \leq 1 / m}|f(t)|(k+1) d t+\int_{1 / m \leq|x-t| \leq 2 \pi}|f(t)| \frac{1}{k(y-t)^{2}} d t\right) .
\end{aligned}
$$

Using (6) for the values $t$, that satisfy (7), we obtain

$$
\begin{aligned}
& \sum_{k=0}^{\infty}(k+1)\left|\Delta^{2} \lambda_{k}(h)\right| \int_{-\pi}^{\pi}|f(t)| F_{k}(y-t) d t \leq C_{\Lambda}\left(f^{*}(x)+\right. \\
& +\sum_{k=1}^{m}(k+1)\left|\Delta^{2} \lambda_{k}(h)\right|\left((k+1) \int_{|x-t| \leq 1 / k}|f(t)| d t \int_{1 / k \leq|x-t| \leq 2 \pi}|f(t)| \frac{1}{k(x-t)^{2}} d t\right)+ \\
& +\sum_{k=m+1}^{\infty} \frac{(k+1)^{2}}{m} \mid \Delta^{2} \lambda_{k}(h)\left(\prod_{|x-t| \leq 1 / m} \mid f(t \mid d t)+\right. \\
& \left.+\sum_{k=m+1}^{\infty}(k+1)\left|\Delta^{2} \lambda_{k}(h)\right| \int_{1 / m \leq|x-t| \leq 2 \pi}|f(t)| \frac{1}{k(x-t)^{2}} d t\right) \leq \\
& \leq C_{\Lambda} f^{*}(x)\left(1+\sum_{k=1}^{m}(k+1)\left|\Delta^{2} \lambda_{k}(h)\right|+\sum_{k=m+1}^{\infty} \frac{(k+1)^{2}}{m}\left|\Delta^{2} \lambda_{k}(h)\right|\right) ;
\end{aligned}
$$

we used the estimate (see eg., [2])

$$
\int_{1 / k \leq x-t \mid \leq 2 \pi}|f(t)| \frac{1}{k(x-t)^{2}} d t \leq C \sum_{j=1}^{S} \frac{k+1}{\left(2^{j-1}\right)^{2}} \underset{\frac{2^{j-1}}{k+1} \leq t \leq \frac{2^{j}}{k+1}}{\int}|f(x+t)| d t \leq C f^{*}(x),
$$

in which the integer $S$ was choosing from the condition

$$
\frac{2^{S-1}}{k+1} \leq \pi<\frac{2^{S}}{k+1} .
$$

The right side of (9), obviously, does not exceeds

$$
C_{\Lambda} f^{*}(x) \sum_{k=0}^{\infty} \frac{(m+k+1)(k+1)}{m}\left|\Delta^{2} \lambda_{k}(h)\right|
$$

which implies the assertion of Theorem 1.

\section{$L^{p}$-estimates}

Let

$$
\|f\|_{p}=\left(\int_{-\pi}^{\pi}|f(x)|^{p} d x\right)^{1 / p}
$$

be a norm in Lebesgue space $L^{p}\left(p>0 ; L=L^{1} ;\|f\|=\|f\|_{1}\right)$.

Theorem 2. If the sequence $\Lambda$ satisfies the conditions (2) and (3), the following estimates 


$$
\begin{aligned}
& \left\|U_{*}(f)\right\|_{p} \leq C_{p, \Lambda}\|(f)\|_{p}, \quad p>1 ; \\
& \left\|U_{*}(f)\right\| \leq C_{\Lambda}\left(1+\left\|f\left(\ln ^{+}|f|\right)\right\|\right) ; \\
& \left\|U_{*}(f)\right\|_{p} \leq C_{p, \Lambda}\|(f)\|, \quad 0<p<1 .
\end{aligned}
$$

hold.

The result follows from Theorem 1 and the corresponding $L^{p}$-estimates of maximal Hardy function (see [4, vol. 1, p. 60]).

\section{Non-tangential convergence}

Theorem 3. If $f \in L_{2 \pi}$, the sequence $\Lambda$ satisfies (2), (3) and

$$
\lim _{h \rightarrow 0} \lambda_{k}(h)=1, k=0,1, \ldots,
$$

then the relation

$$
\lim _{\substack{(y, h) \rightarrow(x, 0) \\(y, h) \in \Gamma_{d}(x)}} U(f, y ; \lambda, h)=f(x)
$$

holds almost everywhere.

The theorem can be proved by the standard method [4, vol. 2, p. 464-465]. Scheme of the proof is as follows. By (11) the relation of form (12), as is easily seen, accomplishes uniformly over $(y, h)$ for every $f(y)=T(y)$; here $T(y)$ is any trigonometric polynomial. Next, choose $T(x)$ such as a norm $\|\varphi\|$, where $\varphi(x)=f(x)-T(x)$, has been prescribed small. Now

$$
\begin{gathered}
|U(f, y ; \lambda, h)-f(x)|=|U(T, y ; \lambda, h)+U(\varphi, y ; \lambda, h)-T(x)-\varphi(x)| \leq \\
\leq|U(T, y ; \lambda, h)-T(x)|+U_{*}(\varphi, x ; \lambda)+|\varphi(x)| .
\end{gathered}
$$

By (13), (10) and the choice of the polynomial $T$, the measure of those $x$ for which $|U(f, y ; \lambda, h)-f(x)|$ is more even a small number, will be prescribed small. This is the satisfiability of relation (12) for almost all $x$.

\section{Exponential means}

Denote now

$$
\lambda_{0}(h)=1, \lambda_{k}(h)=\left.\lambda(x, h)\right|_{x=k}, k=1,2, \ldots,
$$

where $\lambda(x, h)=\exp (-h \varphi(x))$, and require the following conditions:

a) $\varphi \in C^{2}(0,+\infty) ; \varphi(x) \geq 0, \varphi^{\prime}(x) \geq 0, \varphi^{\prime \prime}(x) \geq 0, x \in(0,+\infty)$;

b) $x^{2}\left(\varphi^{\prime}(x)\right)^{2} \exp (-h \varphi(x))$ and $x^{2}\left|\varphi^{\prime \prime}(x)\right| \exp (-h \varphi(x))$ decrease to zero as $x$ increases.

Note that

$$
\lambda_{x}^{\prime \prime}(x, h)=h \exp (-h \varphi(x))\left(h\left(\varphi^{\prime}(x)\right)^{2}-\varphi^{\prime \prime}(x)\right) .
$$

and apply twice the Lagrange theorem to the second finite differences in (9).

Under the conditions of B) the right side of (9) is majorized by the sum of corresponding improper integral and for implementability of statements of Theorems 1 , 2 and 3 (with the additional condition (11)) is sufficient to require

$$
\int_{0}^{\infty}\left(h^{2}\left(\varphi^{\prime}(x)\right)^{2}+h\left|\varphi^{\prime \prime}(x)\right|\right) x \exp (-h \varphi(x)) d x+
$$




$$
+h \int_{0}^{\infty}\left(h^{2}\left(\varphi^{\prime}(x)\right)^{2}+h\left|\varphi^{\prime \prime}(x)\right|\right) x^{2} \exp (-h \varphi(x)) d x \leq C_{\varphi},
$$

i.e.

$$
\int_{0}^{\infty}\left(h^{2}\left(\varphi^{\prime}(x)\right)^{2}+h\left|\varphi^{\prime \prime}(x)\right|\right)\left(x+h x^{2}\right) \exp (-h \varphi(x)) d x \leq C_{\varphi} .
$$

\section{Generalized Poisson-Abel means}

Consider in particular the case of $\varphi(x)=x^{\alpha}, \alpha \geq 1$, then

$$
\lambda_{0}(h)=1, \lambda_{k}(h)=\exp \left(-h k^{\alpha}\right), \quad k=1,2, \ldots ; \alpha \geq 1 .
$$

Corollary 1. The statements of Theorems 2 and 3 are valid for generalized Poisson-Abel means

$$
\sigma(f, y ; \alpha, h)=\sum_{k=-\infty}^{\infty} \exp \left(-h|k|^{\alpha}\right) c_{k}(f) \exp (i k y) \text { for all } \alpha \geq 1 ;
$$

the constants $C$ in the estimates of $L^{p}$-norms is $C=C_{\alpha, p}$.

In particular, the relation

$$
\lim _{\substack{(y, h) \rightarrow(x, 0) \\ y, h) \in \Gamma_{d}(x)}} \sum_{k=-\infty}^{\infty} \exp (-h|k|) c_{k}(f) \exp (i k y)=f(x), f \in L_{2 \pi},
$$

(non-tangential convergence of Poisson-Abel means) holds for almost all $x$.

Remark. Since further arguments related to the integral form of means $\sigma(f, y ; \alpha, h)$, then we also say about generalized Poisson integral.

Proof. Condition a) and b) in this case can be easily verified. To verify the condition (14), we transform the integral

$$
J=h^{s} \int_{0}^{\infty} x^{\beta} \exp \left(-h x^{\alpha}\right) d x
$$

(the values of parameters $s$ and $\beta$ will be chosen later) by the replacing of variables $t=h x^{\alpha}$, to form

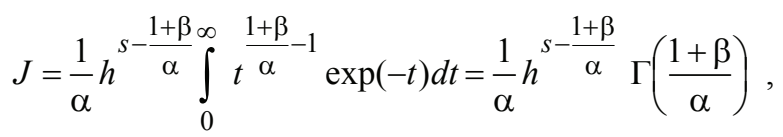

where $\Gamma=\Gamma(\tau)$ is Euler gamma function (converging at $\tau>0$ the improper integral).

In the following four cases (corresponding to four integrals in (14)), we have:

1) $s=2, \beta=2 \alpha-1$; here $J=\frac{1}{\alpha} \Gamma(2)$;

2) $s=1, \beta=\alpha-1$; hence, $J=\frac{1}{\alpha} \Gamma(1)$;

3) $s=3, \beta=2 \alpha$; then $J=\frac{1}{\alpha} h^{1-\frac{1}{\alpha}} \Gamma\left(2+\frac{1}{\alpha}\right)$;

4) $s=2, \beta=\alpha$; hence, $J=\frac{1}{\alpha} h^{1-\frac{1}{\alpha}} \Gamma\left(1+\frac{1}{\alpha}\right)$. 
Now sum (3) is no more

$$
C_{\alpha}\left(1+h^{1-\frac{1}{\alpha}}\right),
$$

so that the sequence (15) satisfies the condition (3), from which follows the assertion of Corollary 1.

\section{Exponentially-polynomial summation methods}

Let now $\varphi(x)$ is a polynomial function of $n$-th degree

$$
P_{n}(x)=a_{n} x^{n}+a_{n-1} x^{n-1}+\ldots+a_{0}, \quad a=a_{n}>0 ; n=1,2, \ldots
$$

Corollary 2. The assertions of Theorems 2 and 3 are valid for exponentiallypolynomial means

$$
\sigma(f, y ; n, h)=\sum_{k=-\infty}^{\infty} \exp \left(-h P_{n}(|k|)\right) c_{k}(f) \exp (i k y) \text { for all } n=1,2, \ldots
$$

the constants $C$ in the estimates of $L^{p}$-norms is $C=C_{n, p}$.

Proof. It suffices to verify conditions a) and b) and the boundedness of sums in (9); while the sum in (9) can be viewed at $k \in[v,+\infty)$, where $v$ is fixed natural number, which will be chosen later.

Since $a=a_{n}>0$ and

$$
P_{n}(x)=x^{n}\left(a+\frac{a_{n-1}}{x}+\ldots+\frac{a_{0}}{x^{n}}\right),
$$

then for sufficiently large values of $x$

$$
P_{n}(x)>\frac{a}{2} x^{n}
$$

holds.

Similarly, for sufficiently large values of $x$ we have

$$
P_{n}^{\prime}(x)>0 \text { and } P_{n}^{\prime \prime}(x)>0 .
$$

Let now $v$ be a positive integer such that for $x \geq v$ at the same time the relations (16) and (17) hold; we can assume that $v<m$. With these $x$ the conditions a) of Sec. 6 are valid.

We now turn to the conditions b). For $\varphi(x)=P_{n}(x)$ the required estimates follow easily from the obvious inequalities

$$
\left(P_{n}{ }^{\prime}(x)\right)^{2} \leq C_{n} x^{2 n-2},\left|P_{n}^{\prime \prime}(x)\right| \leq C_{n} x^{n-2} \text { for } x \geq 1
$$

and (see (16))

$$
\exp \left(-h P_{n}(x)\right)<\exp \left(-h \frac{a}{2} x^{n}\right)
$$

The proof of the boundedness of the integrals in (14) follows now from (18) and (19), by the same arguments that were used in Sec. 6 for a generalized Poisson integral. 


\section{References}

1. Bausov L.I. Matematicheskii sbornik (Sbornik: mathematics), 1965, vol. 68 (110), no. 3, pp. 313-327.

2. Nakhman A.D., Osilenker B.P. Transactions of Tambov State Technical University, 2014, vol. 20, no. 1, pp. 101-109.

3. Osilenker B.P., Nakhman A.D. Vestnik MGSU, 2014, no. 10, pp. 54-63.

4. Zygmund A. Trigonometricheskie ryady (Trigonometric Series) : Cambridge University Press, 1959.

\section{Нетангенциальная сходимость обобщенного интеграла Пуассона}

\section{А. Д. Нахман ${ }^{1}$, Б. П. Осиленкер ${ }^{2}$}

Кафедры:: «Техническая механика и детали машин», ФГБОУ ВПО «ТГТУ» (1); «Высшая математика», ФГБОУ ВО «Московский государственный строительный университет» (2); alextmb@mail.ru

Ключевые слова: нетангенциальная сходимость; полунепрерывные средние; экспоненциальные методы суммирования.

Аннотация: Рассматриваются средние $U(f, y ; \lambda, h)$ рядов Фурье, порожденные полунепрерывными методами суммирования $\Lambda=\left\{\lambda_{k}(h), k=0,1, \ldots\right.$; $h>0\}$. Для $(y, h)$, принадлежащих «угловой» области $\Gamma_{d}(x)$, получены верхние оценки соответствующих максимальных операторов. Установлена нетангенцильная сходимость почти всюду обобщенных средних Пуассона Абеля, соответствующих случаю $\lambda_{k}(h)=\exp \left(-h k^{\alpha}\right), k=0,1, \ldots ; \alpha \geq 1$.

\section{Список литературы}

1. Баусов, Л. И. О линейных методах суммирования рядов Фурье / Л. И. Баусов // Математический сборник. - 1965. - Т. 68(110), № 3. - С. 313 - 327.

2. Nakhman, A. D. Exponential Methods of Summation of the Fourier Series / A. D. Nakhman, B. P. Osilenker // Вест. Тамб. гос. техн. ун-та. - 2014. - Том 20, № 1. - C. $101-109$.

3. Осиленкер, Б. П. Поведение экспоненциальных средних рядов Фурье и сопряженных рядов Фурье в точках Лебега / Б. П. Осиленкер, А. Д. Нахман // Вест. МГСУ. - 2014. - № 10. - С. 54 - 63.

4. Зигмунд, А. Тригонометрические ряды : пер. с англ. : в 2 т. / А. Зигмунд. М. : Мир, 1965.

\section{Nichttangentiale Konvergenz des verallgemeinerten Integrals von Poisson}

Zusammenfassung: Es werden die mittleren $U(f, y ; \lambda, h)$ der Fourierreihen, die von den halbununterbrochenen Methoden der Summierung von $\Lambda=\left\{\lambda_{k}(h)\right.$, $k=0,1, \ldots ; h>0\}$ erzeugt sind, betrachtet. Für $(y, h)$, die zu "dem Winkelgebiet" 
gehören, sind die oberen Einschätzungen der entsprechenden maximalen Operatoren erhalten. Es ist die nichttangentiale Konvergenz der fast überall verallgemeinerten mittleren von Poisson-Abel, die dem Fall $\lambda_{k}(h)=\exp \left(-h k^{\alpha}\right), \quad k=0,1, \ldots ; \quad \alpha \geq 1$ entsprechen, bestimmt.

\section{Convergence non-tangentielle d'un intégrale généralisé de Poisson}

Résumé: Sont considérées les moyennes $U(f, y ; \lambda, h)$ des séries de Fourier, générées par les méthodes semi-continues de la sommation $\Lambda=\left\{\lambda_{k}(h), k=0,1, \ldots\right.$; $h>0\}$. Pour $(y, h)$ appartenant au domaine angulaire $\Gamma_{d}(x)$ sont obtenues les valeurs supérieures des opérateurs maximums. Est établie la convergence non-tangentielle des moyennes généralisées presque partout de Poisson-Abel, correspondant au cas $\lambda_{k}(h)=\exp \left(-h k^{\alpha}\right), \quad k=0,1, \ldots ; \alpha \geq 1$.

Авторы: Нахман Александр Давидович - кандидат физико-математических наук, доцент кафедры «Техническая механика и детали машин», ФГБОУ ВПО «ТГТУ»; Осиленкер Борис Петрович - доктор физико-математических наук, профессор кафедры высшей математики, ФГБОУ ВО «Московский государственный строительный университет», г. Москва.

Рецензент: Куликов Геннадий Михайлович - доктор физико-математических наук, профессор, заведующий научно-исследовательской лабораторией «Механика интеллектуальных материалов и конструкций», ФГБОУ ВПО «ТГТУ». 